\title{
Thermal Transport Properties Analysis of MWCNT-RT21Nanofluids
}

\author{
V. Vigneshwaran, V. K. Aravindraman, K. Venkatachalam, V. Raveendran \\ Assistant Professor, Department of Mechanical Engineering, \\ Smk Fomra Institute of Technology, Tamil Nadu, India
}

\begin{abstract}
Phase change materials find potential application in the field of Heating ventilation and air conditioning (HVAC). Paraffin, one ofthe commonly used organic phase change material exhibits high thermal storage capacity, chemical stability and low sub cooling. The major limitation despite the above merits is its poor thermal conductivity. The main aim of this work is to improve the thermal transport properties of the phase change material (Paraffin RT21) by dispersing Multiwall Carbon Nanotube (MWCNT) nanoparticles in it. The thermal properties and rheological properties of the nanofluid for different volume fractions of MWCNT in the presence and absence of surfactant were evaluated. The result explicates that the efficiency of the nanofluid with MWCNT nanoparticles are in the better side than the Paraffin RT21.
\end{abstract}

Keywords: Multiwall Carbon Nanotubes (MWCNT), volume fraction, Paraffin RT21, thermal conductivity, rheological properties

\section{INTRODUCTION}

Latent heat storage system employing phase change materials is one of the energy saving technology. The process of storing the cool energy after the sunset and releasing the same for cooling the buildings during daytime is referred as free cooling, which created drastic changes in the field of Heating ventilation and air conditioning. The thermal conductivity of Paraffin can be enhanced by increasing the surface area of the system by addition of fins or tabulator. Solomon et al. [2] reported the enhancement in heat transfer of the thermal storage system by adding fins to the double pipe heat exchanger and using paraffin as PCM.

The thermal conductivity of the base fluid are enhanced by dispersing the nanoparticles into the base fluid. This method of enhancing heat transfer was initiated by Choi et al. [3].

Nanoparticles of $\mathrm{CuO}, \mathrm{Al}_{2} \mathrm{O}_{3}$, Titanium Oxide, silver oxide etc., exhibits good thermal conductivity, electrical conductivity. Multiwall Carbon Nanotube(MWCNT), the polymers of pure carbon is most suitable nanoparticle for dispersion in paraffin as the base fluid but preparing MWCNT nanofluids with enhanced stability is a challenge,

Kumaresan et al. [4] and Lajvardi et al. [5] dispersed the MWCNT nanoparticle in paraffin by two step method.The thermal properties for varying volume fraction of MWCNT's nanofluids were evaluated.

The main objective of this research work is to prepare MWCNT- Paraffin RT21 based nanofluid by two step method in the presence of surface modifier. The thermal conductivity, thermal resistivity, viscosity, shear stress and density of the MWCNT based nanofluid were evaluated for varying volume fractions of MWCNT's.

\section{Material and Methods}

Paraffin RT21 purchased from Rubitheium Technologies, Germany, was employed as phase change material. Multiwall Carbon Nanotube (MWCNT) was purchased from AD-
Nanotech, Karnataka, India which was synthesis by chemical vapour deposition method by the manufacturer. The surfactant used in the nanofluid preparation is Polysorbate80.

The procedure involves dispersion of MWCNT in Paraffin RT-21using magnetic stirrer at around $300 \mathrm{rpm}$ for 30 minutes at ambient temperature followed by the addition of Polysorbate-80. The contents were subjected to sonication using probe sonicator (Leela Sonic-250W, India) for 20 minutes. Stability of the nanofluids was studied by visual method (sedimentation by gravity with respect to time, when kept undisturbed). The thermal conductivity of the nanofluid was studied at different temperatures using transient hot-wire method by KD-2 Pro thermal property analyser (Manufacturer: Decagon Devices)[4,7]. The rheological parameters such as viscosity and shear stress of the fluid at different temperatures were studied using Brookfield DV111 ultra programmable rheometer[7].

\section{Result and Discussion}

Paraffin RT21 is selected for the present investigation, since, its melting point is $21^{\circ} \mathrm{C}$ with heat storage capacity of 155 $\mathrm{kJ} / \mathrm{kg}$ and hence, it acts as an ideal phase change material at room temperature. MWCNT-Paraffin RT21 nanofluids were prepared by varying the MWCNT concentration in the range $0.1 \%$ to $0.5 \%$ volume fraction. When the stability studies were carried out with the above fluids, it was observed that the nanofluid with more than $0.5 \%$ of MWCNT separated into two layers after 2 weeks, while that prepared with $0.1 \%$, $0.2 \%, 0.3 \%$ and $0.4 \%$ were stable for more than 3 months. In general, the addition of surfactant decreases the thermal conductivity of the nanofluids and hence the concentration was kept to a minimum of $0.3 \%$, below which the nanofluid was found to be unstable. The sonication time plays a vital role in stabilizing the fluid. For the given volume of $100 \mathrm{~mL}$, with $5 \mathrm{~mm}$ SS probe, it was found that sonication time of less than 20 minutes formed unstable nanofluid. 


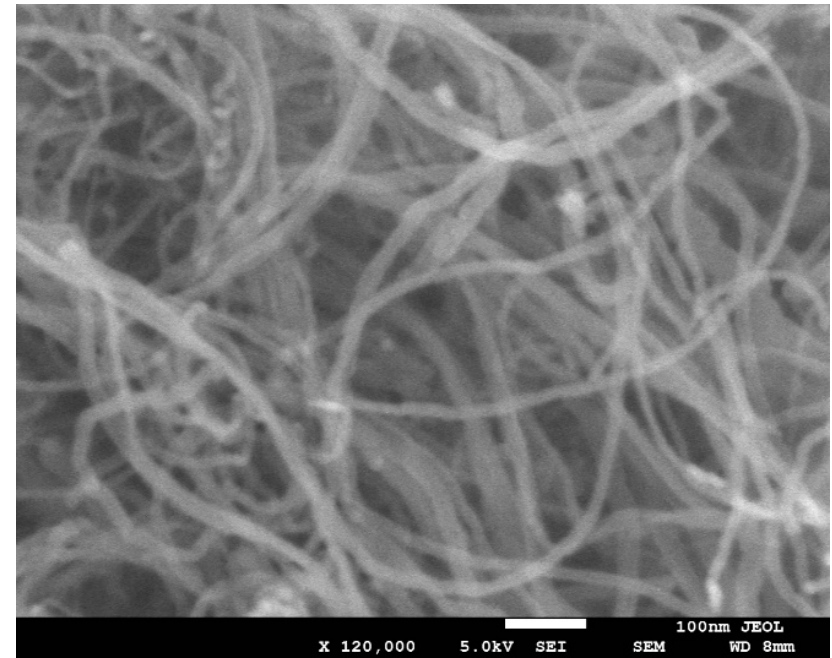

Fig. 1: SEM image of MWCNT

The SEM image of the MWCNT was provided by the manufacturer and given in Fig.1. It is clear from the image that thickness of MWCNT is in the range of $10-20 \mathrm{~nm}$.

Thermal conductivity of the MWCNT-Paraffin RT21 based nanofluid wasevaluated at different temperatures and the data is presented in Table 1.

Table 1: Thermal conductivity of MWCNT-Paraffin RT21 nanofluids

\begin{tabular}{|c|c|c|c|c|c|c|}
\hline & & \multicolumn{3}{|c|}{ Thermal Conductivity, W/mK } \\
\cline { 3 - 7 } S & \multirow{2}{*}{$\begin{array}{c}\text { Sample } \rightarrow \\
\text { Tempera } \\
\end{array}$} & $\begin{array}{c}\text { Paraffin } \\
\text { ture }\end{array}$ & \multicolumn{4}{|c|}{ MWCNT concentration in } \\
\cline { 3 - 7 } & & $\mathbf{0 . 1 \%} \%$ & $0.2 \%$ & $0.3 \%$ & $\mathbf{0 . 4 \%}$ \\
\hline 1. & $20^{\circ} \mathrm{C}$ & 0.143 & 0.138 & 0.143 & 0.149 & 0.157 \\
\hline 2. & $25^{\circ} \mathrm{C}$ & 0.163 & 0.153 & 0.168 & 0.189 & 0.212 \\
\hline 3. & $30^{\circ} \mathrm{C}$ & 0.187 & 0.188 & 0.199 & 0.231 & 0.316 \\
\hline
\end{tabular}

The thermal conductivity was found to increase with increase in concentration of MWCNT and with increase in temperature. A maximum enhancement of thermal conductivity to an extent of more than $100 \%$ was observed for nanofluid with $0.4 \%$ MWCNT at $30^{\circ} \mathrm{C}$. The graphical representation of the data is presented in Fig.2. It can be inferred from the figure, that the nanofluids with MWCNT of $0.3 \%$ and above showed significance increase in the thermal conductivity, below which it was nearly equal to that of the base fluid (Paraffin RT21).

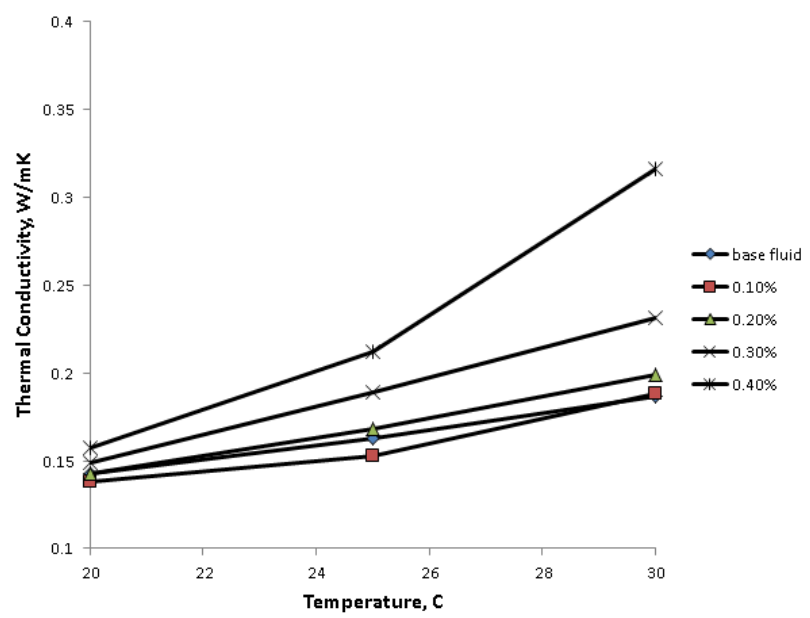

Fig. 2: Effect of temperature on thermal conductivity on MWCNT nanofluids
The Fig. 2 gives graphical representation of influence of MWCNT concentration on thermal conductivity. It can be seen that addition of MWCNTdid not influence much at $20^{\circ} \mathrm{C}$, while the same at $30^{\circ} \mathrm{C}$ increase significantly and $0.3 \%$ and reached maximum at $0.4 \%$.

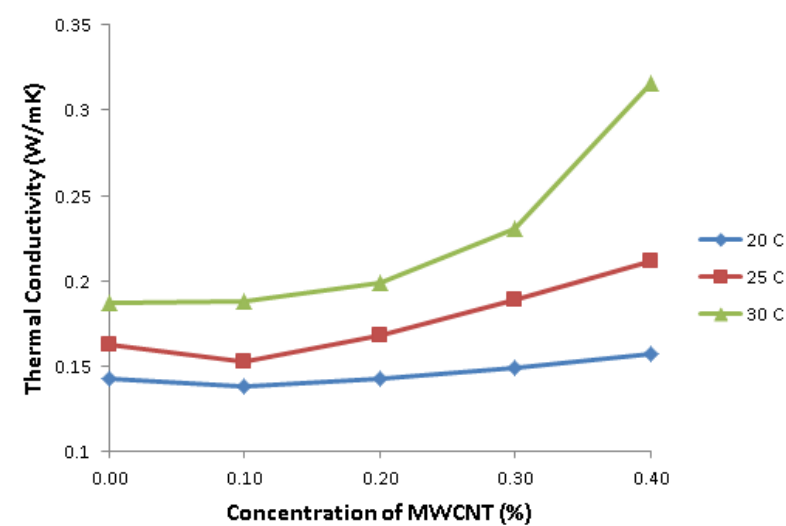

Fig. 3: Effect of concentration of MWCNT on thermal conductivity at different temperatures.

Influence of MWCNT concentration on rheological parameters of nanofluids were studied and presented in Fig.4.

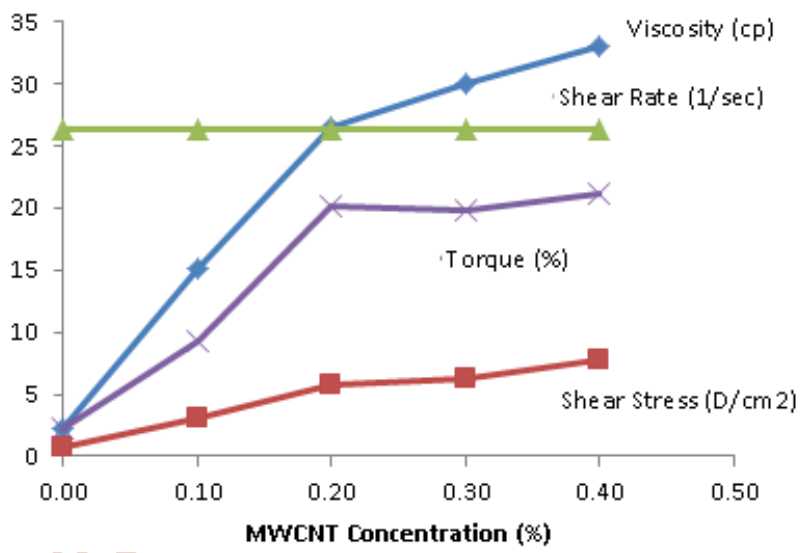

Fig. 4: Influence of MWCNT concentration of rheological properties of nanofluids

The viscosity and torque of the nanofluid was found to increase with increase in MWCNT concentration, while the shear stress and shear rate was found to be nearly constant.

\section{Conclusion}

Nanofluids were prepared by dispersing MWCNT in Paraffin RT21 base fluid using suitable surfactant under optimized conditions. The prepared sample was found to be highly stable (without formation of sediments) upto MWCNT content of $0.4 \%$ which showed enhancement of thermal conductivity to an extent of $120 \%$. The rheological properties of the nanofluids were studied.

\section{References}

[1] Belen Zalba, Jose Ma Marın a, Luisa F. Cabeza, Harald Mehling" Review on thermal energy storage with phase Change: materials, heat transfer analysis and applications" Pergamon, Applied Thermal Engineering 23 (2003) 251-283

[2] GnanaduraiRavikumar Solomon and RamalingamVelraj, "Analysis of the heat transfer mechanisms during energy 
International Journal of Trend in Scientific Research and Development (IJTSRD) @ www.ijtsrd.com eISSN: 2456-6470

storage in a phase change material filled vertical finned cylindrical unit for free cooling application" Energy Conversion and Management, vol 75, pp 466-473,2013.

[3] Stephen U. S. Choi1 and J. A. Eastman2 "Enhancing thermal conductivity of fluids with nanoparticles" ASME FED-Vol. 231/MD-Vol 66 (1995) 99.

[4] VellaisamyKumaresan, RamalingamVelraj, Sarit k. Das "the effect of carbon nanotubes in enhancing thermal transport properties of PCM during solidification" springer heat and mass transfer DOI 10.1007/s00231012-0980-3

[5] Lajvardi, F.Zabihi, H.Faraji, I.Hadi, J.Mollai "The Effect of Phase Change Material in Nanofluids Heat Transfer" proceedings of the $4^{\text {th }}$ International Conference on Nanostructures" 12-14 March, 2012 , Kish Island, I.R.Iran

[6] Min-Sheng Liu a, Mark Ching-Cheng Lin b, I-Te Huang a, Chi-Chuan Wang a, "Enhancement of thermal conductivity with carbon nanotube for nanofluids" Elsevier International Communications in Heat and Mass Transfer 32 (2005) 1202-1210.

[7] Kamaldeep Singh, Sumeet Sharma, D.Gangacharyalu "Experimental study of thermo physical properties of $\mathrm{Al}_{2} \mathrm{O}_{3}$ /water nanofluid" IJRMET Vol 3, Issue 2, May -Oct 2013

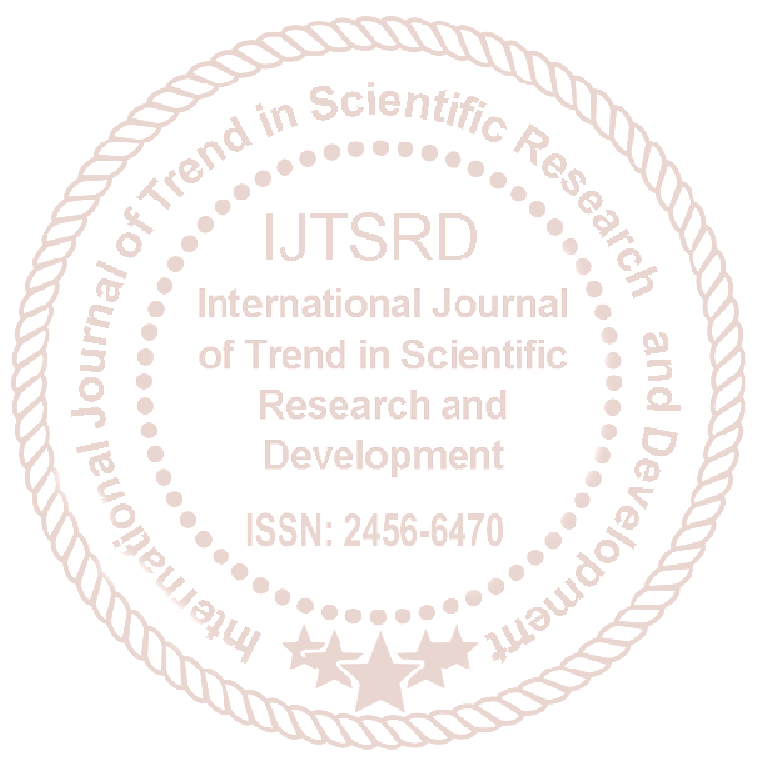

